\title{
Nota sobre o gênero Chlamophora Chevrolat, com a descrição de uma nova espécie do sul do Brasil (Coleoptera, Chrysomelidae, Galerucinae)
}

\author{
Luciano de A. Moura \\ Museu de Ciências Naturais, Fundação Zoobotânica do Rio Grande do Sul. Rua Dr. Salvador França 1427, 90690-000 Porto \\ Alegre, Rio Grande do Sul, Brasil. E-mail: luciano.moura@fzb.rs.gov.br
}

\begin{abstract}
Note on the genus Chlamophora Chevrolat, with description of a new species from south of Brazil (Coleoptera, Chrysomelidae, Galerucinae). A new species of Chlamophora Chevrolat, 1837, Chlamophora potyra sp. nov. from São Francisco de Paula, state of Rio Grande do Sul, Brazil is described and illustrated, including characters of male and female genitalia. This new taxa is near to C. opacicollis Harold, 1880, but differs from the latter mainly by the aedeagus and, in females, by the shape of sternite VIII and vaginal palpi. Specimens of $C$. potyra sp. nov. was collected on inflorescences of Eupatorium inulifolium H.B. \& K. (Asteraceae). Herein, Chlamophora mendesi Bechyné, 1951 is considered junior synonym of Chlamophora generosa Clark, 1865.
\end{abstract}

KEY WORDS. Alticini; host plant; Neotropical; new synonymy; taxonomy.

RESUMO. Uma nova espécie de Chlamophora Chevrolat, Chlamophora potyra sp. nov. de São Francisco de Paula, Estado do Rio Grande do Sul, Brasil é descrita e ilustrada, incluindo caracteres da genitália masculina e feminina. Este novo táxon é próximo a $C$. opacicollis Harold, 1880 , mas difere desta última principalmente pelo edeago e, nas fêmeas, pela forma do esternito VIII e palpos vaginais. Espécimes de $C$. potyra sp. nov. foram coletados em inflorescências de Eupatorium inulifolium H.B. \& K. (Asteraceae). Chlamophora mendesi Bechyné, 1951 é considerado sinônimo-júnior de $C$. generosa Clark, 1865.

PALAVRAS-CHAVE. Alticini; Neotropical; nova sinonimia; planta-hospedeira; taxonomia.

O gênero Chlamophora Chevrolat, 1837 está representado por 20 espécies (SCherer 1983, Cabrera \& Roig-Juñent 1998), a maioria delas distribuídas na América do Sul (apenas duas ocorrem na América Central, FurTh 1996).

Até o momento, informações sobre as plantas-hospedeiras de Chlamophora são escassas e os dois únicos registros limitam-se em mencionar a erva-mate, Ilex paraguariensis St. Hill. (Aquifoliaceae): C. meridionalis Bechyné, 1951 (Silva et al. 1968) e o gênero Chlamophora, sem indicação de espécie (Jolivet 1991).

Nesta contribuição objetiva-se descrever uma nova espécie da região dos Campos de Cima da Serra, Rio Grande do Sul, obtida em sua planta-hospedeira.

$\mathrm{O}$ material estudado pertence às seguintes instituições: Museu de Ciências Naturais, Fundação Zoobotânica do Rio Grande do Sul, Porto Alegre (MCNZ); Museu de Zoologia, Universidade de São Paulo, São Paulo (MZSP); Museu Nacional, Universidade Federal do Rio de Janeiro, Rio de Janeiro (MNRJ) e Coleção de Entomologia Pe. J. S. Moure, Departamento de Zoologia, Universidade Federal do Paraná, Curitiba (DZUP).

\section{Chlamophora potyra sp. nov.}

Figs 1-18, 23-28

Etimologia. Do tupi, potyra = flor, relativo à inflorescência, parte da planta onde os adultos são encontrados.
Macho (Fig. 23). Cabeça com tegumento sub-brilhante, uniformemente amarela, exceto a extremidade apical das mandíbulas (em alguns exemplares também o último segmento dos palpos maxilares), que é castanho-escura a preta; vértice finamente reticulado com um ponto setífero próximo à margem superior de cada um dos olhos. Olhos arredondados, levemente projetados e com maior comprimento cerca de $1,3 \mathrm{vez}$ a maior largura. Tubérculos anteníferos evidentes, brilhantes, dispostos junto à margem superior interna das inserções antenais e separados por uma sutura em forma de Y. Fronte convexa, elevada, com tegumento brilhante e pêlos esparsamente distribuídos. Clípeo curto, com fileira longitudinal de pêlos longos entremeados por pêlos curtos e esparsos; labro encobre parcialmente as mandíbulas, brilhante, com os lados arredondados e borda apical sub-reta, dotado de fileira longitudinal de pêlos longos entremeados de pêlos curtos, todos dispostos na metade apical.

Antenas atingem o terço basal dos élitros, pretas, exceto o escapo ou, em alguns exemplares, também o pedicelo, castanhos. Pubescência curta e escassa nos artículos I e II; a partir dos artículos seguintes, torna-se mais densa e uniforme, com pêlos mais longos na região apical de cada um do artículos (Fig. 1). Escapo subcilíndrico, levemente dilatado para a extremidade, com comprimento aproximadamente 1,5 vez o comprimento do pedicelo; antenômero III mais longo que o II e mais curto 


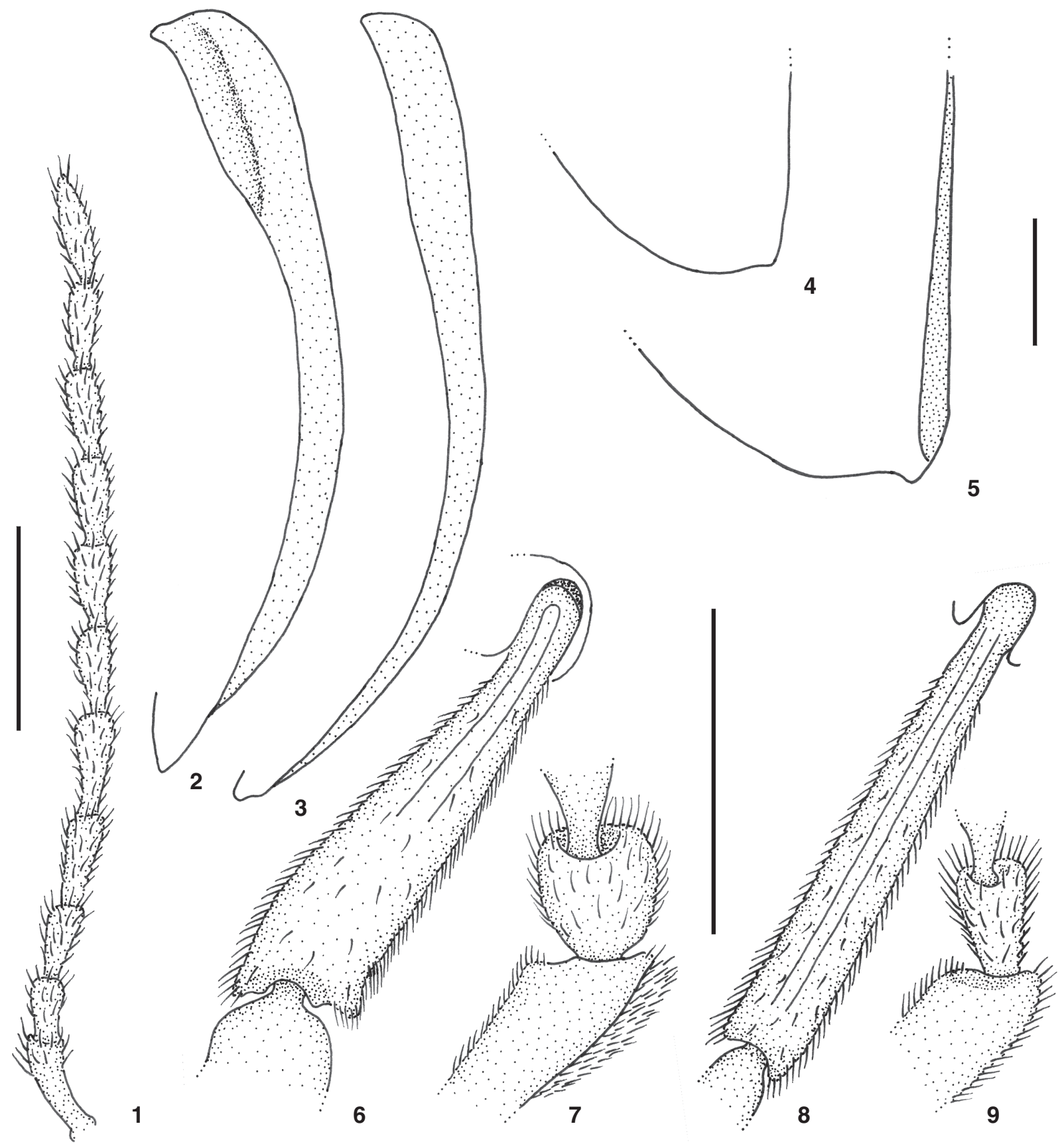

Figuras 1-9. Chlamophora potyra sp. nov.: (1) antena, dorsal; élitro, epipleura: (2) macho; (3) fêmea; élitro, ângulo sutural: (4) macho; (5) fêmea; protíbias e $1^{\circ}$ tarsômero: $(6,7)$ macho; $(8,9)$ fêmea. Escalas: figuras 1 e 5, 2-4, 6-9, respectivamente na mesma escala; barra = 1 mm.

que os segmentos subseqüentes, IV e V equivalentes, VI ao X menores que os dois anteriores e subiguais em comprimento; XI com extremidade acuminada, levemente mais longo que o antenômero anterior (Fig. 1).

Protórax (Fig. 23) amarelo-testáceo, opaco, com tegumen- to micro-reticulado; maior largura do pronoto cerca de 1,75 vez o comprimento, com sulco transversal pouco profundo e disposto centralmente, próximo à margem basal. Margens laterais arredondadas, marginadas e algo expandidas; cada um dos ângulos anteriores e posteriores com um ponto pelífero 


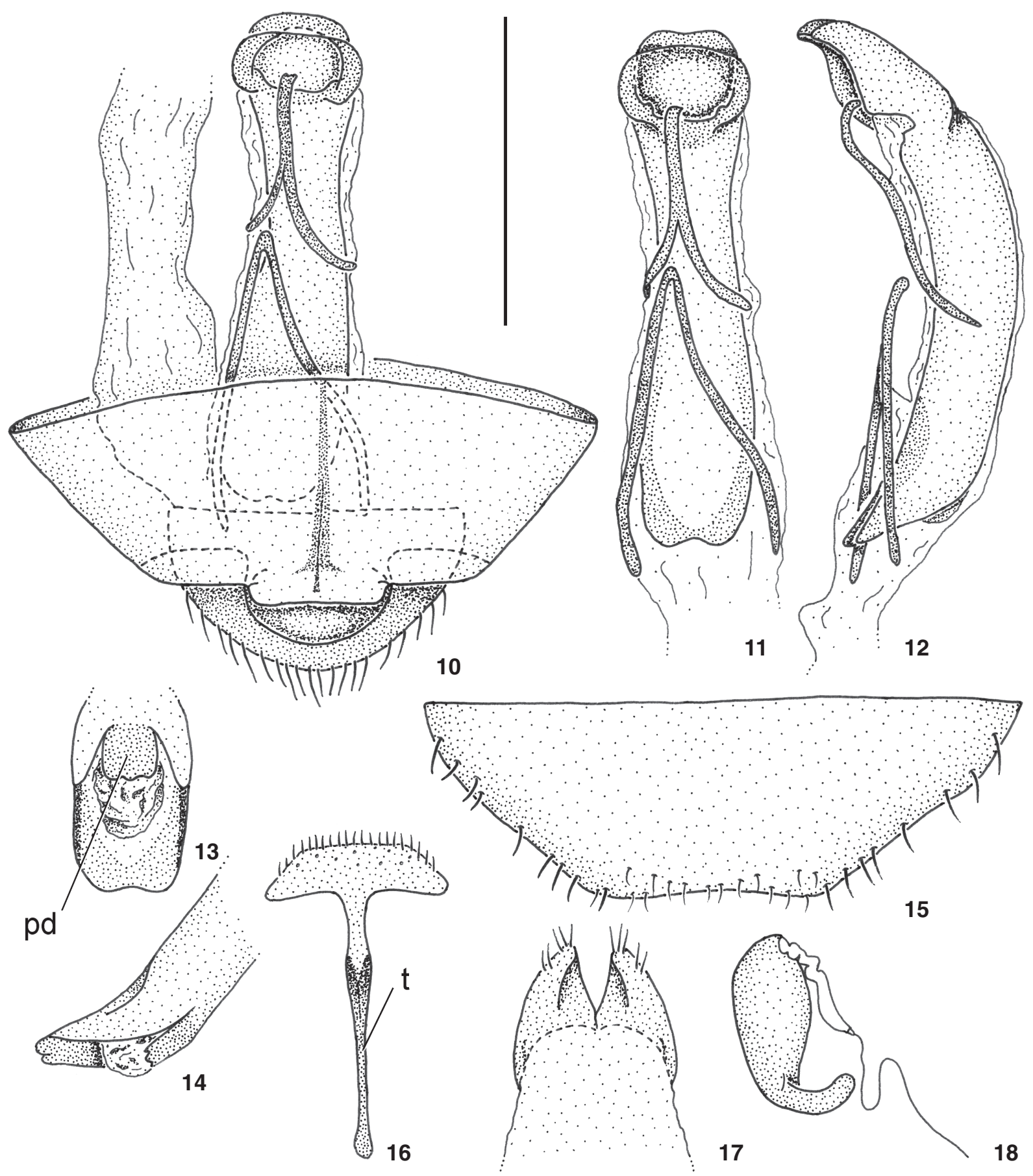

Figuras 10-18. Chlamophora potyra sp. nov. (10-14), macho: (10) ventrito V e genitália; edeago: (11) ventral; (12) lateral; (13) ápice, dorsal; (14) ápice, dorso-lateral. (15-18), fêmea: (15) ventrito V; (16) esternito VIII; (17) palpos vaginais; (18) espermateca. (pd) Placa dorsal, (t) tignum. Barra $=1 \mathrm{~mm}$.

dotado de pêlo longo; ângulos anteriores levemente projetados. Prosterno com pêlos longos e esparsos, estreito, apenas sepa- rando as cavidades coxais anteriores, estas estreitamente abertas atrás; mesosterno encurtado e metasterno cerca do dobro 
do mesosterno, brilhante, com pubescência uniformemente distribuída. Escutelo brilhante, amarelo-testáceo.

Élitros amarelo-testáceos (Fig. 23), opacos, com reticulação menos intensa que a do pronoto e pontuação quase imperceptível, restrita à área discal próxima à sutura. Epipleura (Fig. 2) alargada no terço basal, com uma depressão pouco profunda. Úmeros arredondados. Extremidade elitral com ângulo sutural não-projetado, subarredondado (Fig. 3).

Pernas amarelas, exceto tíbias e tarsos castanho a castanho-escuros, com pubescência curta esparsamente distribuída, mais densa na face ventral das tíbias. Tíbias anteriores (Fig. 6) e intermediárias dilatadas para a extremidade, com a face dorsal plana e brilhante e a ventral convexa; tíbias posteriores apenas engrossadas para o ápice, dotadas de um espinho na extremidade. Primeiro tarsômero dos pro- (Fig. 7) e mesotarsos dilatados, metatarsos normais.

Abdome com pilosidade curta e uniforme, amarelotestáceo, exceto estreita faixa longitudinal no centro do ventrito $\mathrm{V}$, marrom; borda apical do ventrito $\mathrm{V}$ com projeção sub-retangular no centro (Fig. 10).

Genitália. Edeago (Figs 11-14) com lobo-médio cerca de duas vezes o comprimento do tégmen, encurvado e esclerotizado; extremidade apical emarginada centralmente (Figs 11, 13) e, dorsalmente, óstio (abertura por onde extroverte o saco-interno durante a cópula) com placa dorsal ("dorsal plate", Powell 1941) subquadrada, com borda posterior sinuosa (Figs 13, 14). Tégmen hastiforme, com a extremidade basal levemente curva, alojada no orifício basal e, próximo ao meio, bifurcado e divergente (Figs 11, 12). Spiculum gastrale em forma de "V" invertido, envolvendo ventralmente a metade apical do edeago (Figs 10-12).

Fêmea (Fig. 24). Protórax brilhante, finamente reticulado. Élitros sem alargamento ou sulco no terço basal da epipleura (Fig. 3); pontuação escassa e pouco conspícua, mais visível na região próxima à sutura, ou até mesmo ausente em algumas áreas; extremidade elitral com ângulo sutural projetado (Fig. 5). Tíbias anteriores (Fig. 8) e intermediárias similares às posteriores, sem dilatação acentuada para a extremidade. Primeiro tarsômero dos pro- (Fig. 9) e mesotarsos normais, como o do metatarso. Abdome com a borda do ventrito V sub-reta (Fig. 15).

Genitália. Esternito VIII (Fig. 16) subtrapezoidal, com a borda sub-reta dotada de pêlos curtos. Tignum (Konstantinov 1998) (Fig. 16) longo, hastiforme, esclerotizado, levemente dilatado próximo da metade e no ápice; comprimento aproximadamente seis vezes o comprimento do esternito VIII. Palpos vaginais (Fig. 17) subtriangulares, com pêlos curtos esparsamente distribuídos na borda apical. Espermateca (Fig. 18) com a porção basal da cápsula globosa e a apical delgada, encurvada; glândula espermatecal levemente espessada, ducto longo.

Dimensões em milímetros, respectivamente macho/fêmea. Comprimento total, 6,0-7,0/5,9-7,5; comprimento do élitro, 4,7-5,9/4,7-5,7; largura umeral, 2,7-3,2/2,5-3,2.

Material-tipo. Holótipo macho, BRASIL, Rio Grande do Sul: São Francisco de Paula (Boca da Serra, 29²6'38,4"S, 50³7'
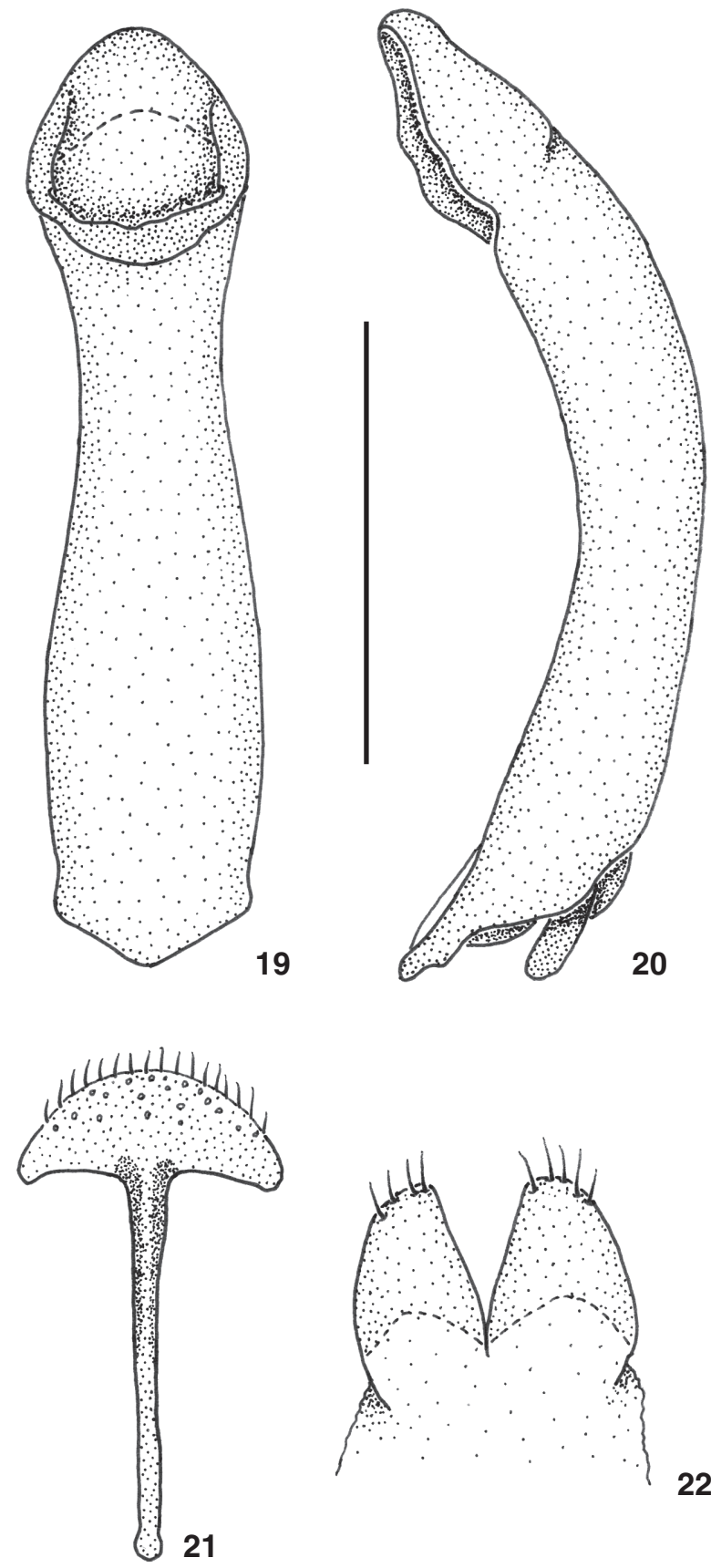

22

Figuras 19-22. Chlamophora opacicollis. (19-20) Macho, lobo médio: (19) ventral; (20) lateral; (21-22) fêmea: (21) esternito VIII; (22) palpos vaginais. Barra $=1 \mathrm{~mm}$.

20 "W), em inflorescência de Eupatorium inulifolium, 1820.IV.2003, L. Moura \& I. Heydrich leg. (MCNZ 221959); parátipos: macho e 4 fêmeas, mesmos dados do holótipo (MCNZ 221954-221958); mesma localidade e planta-hospedeira, 10 

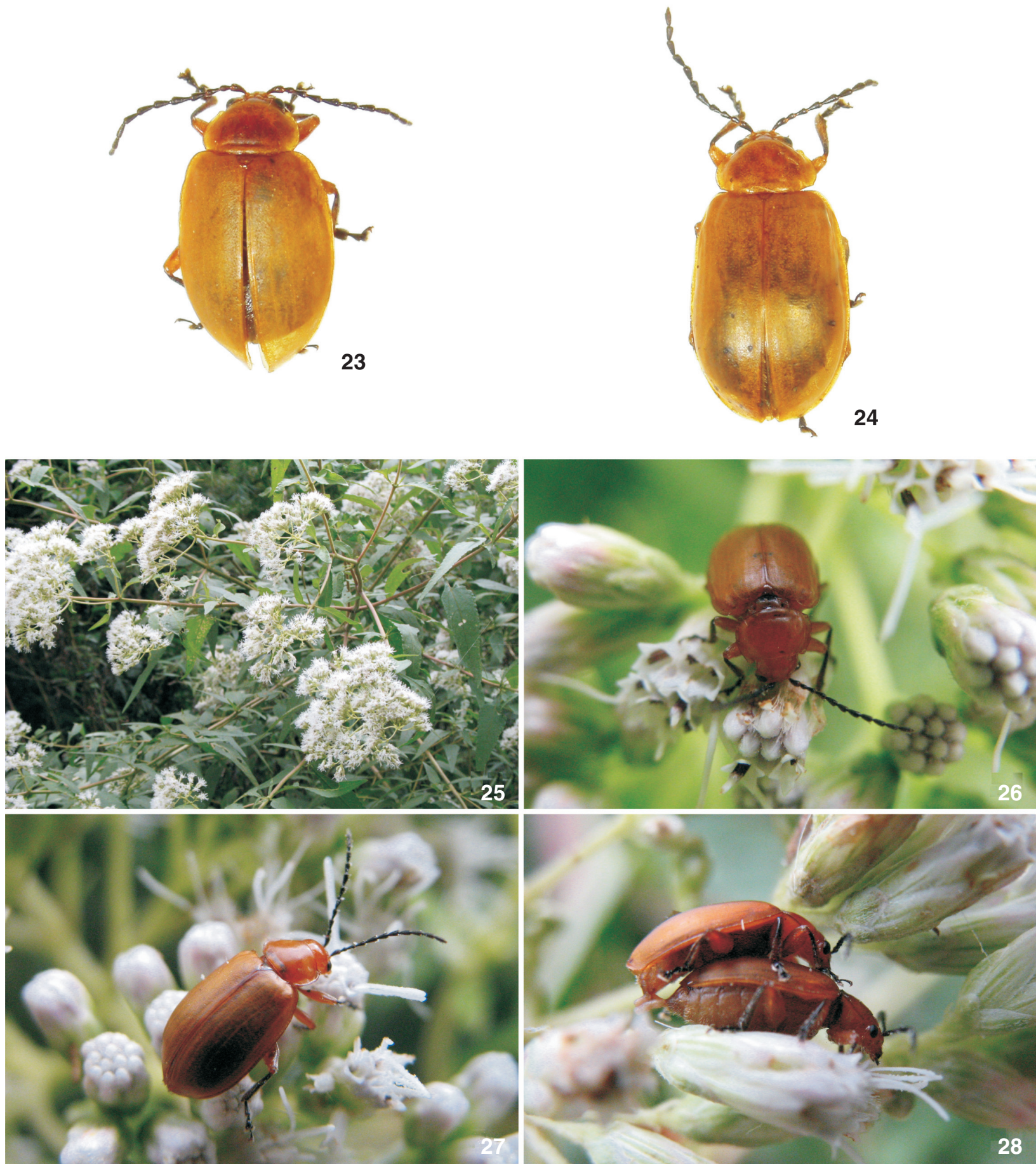

Figuras 23-28. Chlamophora potyra sp. nov.: (23) holótipo macho, 6,5 mm; (24) parátipo fêmea, 7,1 mm; (25) Eupatorium inulifolium, planta-hospedeira; (26) adulto consumindo inflorescência; (27) adulto deslocando-se sobre a inflorescência; (28) casal em cópula.

machos, 12 fêmeas, 10-12.IV.2004, L. Moura leg. (2 machos, 2 fêmeas, DZUP; 2 machos, 2 fêmeas, MZSP; 2 machos, 2 fêmeas, MNRJ; 4 machos, 6 fêmeas, MCNZ 225754, 225756-225758,
225761, 225762, 225764, 225767-225769); 3 fêmeas, mesma localidade e planta-hospedeira, 05.IV.2007, L. Moura \& I. Heydrich leg. (MCNZ 234878-234880).

Revista Brasileira de Zoologia 24 (3): 552-558, setembro 2007 
Discussão taxonômica. Apesar de ter coloração diferente, Chlamophora potyra sp. nov. é similar a C. opacicollis Harold, 1880; ambas espécies apresentam dimorfismo sexual no pronoto opaco nos machos e brilhantes nas fêmeas -, nos élitros, onde a epipleura é alargada e sulcada nos machos, aliado às pro-tíbias e ao primeiro pro- e mesotarsômero, que são dilatados nos machos e normais nas fêmeas. Porém, no edeago de C. opacicollis o lobo-médio (Figs 19, 20) possui configuração diferente da apresentada por C. potyra sp. nov.: (1) a região onde se abre o orifício basal possui a borda distal arredondada (Figs 19, 20); (2) o ápice é levemente projetado (Fig. 19) e (3) a placa dorsal é subtriangular, truncada no ápice; em C. potyra sp. nov., a região do lobo-médio onde se abre o orifíco basal possui a borda distal sub-reta, emarginada no centro, o ápice é emarginado centralmente e a placa dorsal é subquadrada, com borda posterior sinuosa. Além disso, nas fêmeas de C. opacicollis os élitros são pontuados, apresentam vestígios de carenas longitudinais, o esternito VIII (Fig. 21) é semi-circular com a borda arredondada, tignum sem dilatação acima da metade e os palpos vaginais são subglobosos (Fig. 22); em C. potyra, a pontuação dos élitros é escassa e pouco conspícua, mais visível na região próxima à sutura, estando até mesmo ausente em algumas áreas.

Planta-hospedeira e observações in loco. Os exemplares foram coletados em Eupatorium inulifolium H.B. \& K. (Asteraceae), um arbusto de 1 a 2,5 metros de altura conhecido popularmente como cambará (BACKes \& NARdino 1999) (Fig. 25). Todas as plantas que continham indivíduos estavam - ao menos no momento da observação e da captura dos insetos -, isentas da incidência do sol.

A maioria dos exemplares coletada foi encontrada entre as inflorescências, onde eram observados se alimentando (Fig. 26) ou percorrendo os ramos; de forma mais esporádica, indivíduos foram registrados se locomovendo sobre as inflorescências (Fig. 27). Em uma das ocasiões também foi assinalado um casal em cópula, com o macho agarrado à fêmea por meio das pernas anteriores e intermediárias e mantendo as pernas posteriores erguidas (Fig. 28).

Quanto à alimentação, foi verificado que os adultos se alimentam tanto da região basal como da apical das inflorescências (Fig. 26). Não foram encontradas posturas em qualquer região da planta e muito menos larvas ou danos, exceto aqueles das inflorescências, ocasionados pelos adultos. No entanto, mesmo que indivíduos adultos se alimentem das inflorescências de Eupatorium inulifolium, não se pode inferir que as formas imaturas também venham a consumir este item alimentar. Novas observações devem ser feitas objetivando a busca de subsídios para o conhecimento da biologia da espécie.

\section{Chlamophora generosa Clark, 1865}

Chlamophora generosa Clark, 1865: 384.

Chlamophora mendesi Bechyné, 1951: 102 Syn. nov.

Ao descrever Chlamophora mendesi, BEchyné (1951) caracterizou o novo táxon com base somente em fêmeas; no acervo do
MZSP, além de verificarmos representantes de Chlamophora gloriosa e C. mendesi determinados por Bechyné, encontramos ainda entre o material indeterminado seis exemplares (cinco machos e uma fêmea) da localidade-tipo de $C$. mendesi (Itatiaia, Estado do Rio de Janeiro); ao compararmos o exemplar identificado como C. mendesi - e os exemplares indeterminados - com C. generosa, constatamos que na realidade não se trata de espécies distintas e sim um evidente dimorfismo sexual: (1) os élitros nos machos são dorsalmente brilhantes e lateralmente opacos; nas fêmeas, os élitros são inteiramente brilhantes; (2) o primeiro tarsômero das pernas anteriores e intermediárias são dilatados nos machos e nas fêmeas tal estrutura é normal, sem dilatação; (3) o sulco transversal na base do pronoto é mais definido nas fêmeas que nos machos, onde é mais superficial; com base no exposto, as fêmeas descritas por Bechyné como C. mendesi correspondem a C. generosa, espécie que também ocorre no Itatiaia.

Material examinado. BRASIL, Rio de Janeiro: Itatiaia, X.1961, Dirings leg., macho (MZSP); X.1965, Dirings leg., 5 machos, fêmea (MZSP); Minas Gerais: Serra dos Cochos (sul de Minas, 1460 m), sem data, B. Pohl leg., fêmea (MZSP); Santa Catarina: Rio Vermelho, I.1952, Dirings leg., fêmea (MCNZ).

\section{AGRADECIMENTOS}

A Rosana M. Senna (Seção de Botânica, MCNZ) pela identificação da planta-hospedeira; a Ingrid Heydrich (Seção de Invertebrados, MCNZ), pelas imagens digitais obtidas em campo; a Eleandro Moysés (Seção de Invertebrados, MCNZ), pelo tratamento das imagens e elaboração das pranchas.

\section{REFERÊNCIAS BIBLIOGRÁFICAS}

BACKES, A. \& M. NARDINO. 1999. Nomes populares e científicos de plantas do Rio Grande do Sul. São Leopoldo, Unisinos, 202p.

Bechyné, J. 1951. Chrysomeloidea americains nouveaux ou peu connus. Revista Chilena de Entomologia 1: 75-112.

Cabrera, N. \& S. Roig-Juñent. 1998. Chrysomelidae y Megalopodidae, p. 244-257. In: J.J. MORRONE \& S. COSCARÓN (Eds). Biodiversidad de artrópodos argentinos - una perspectiva biotaxonómica. La Plata, Ediciones Sur, 599p.

Clark, H. 1865. An examination of the Halticidae of South America. Journal of Entomology 2: 375-412.

Furth, D.G. \& V. SAVINI. 1996. Checklist of the Alticinae of Central America, including Mexico (Coleoptera: Chrysomelidae). Insecta Mundi 10 (1-4): 45-68.

Jolivet, P. 1991. Sélection trophique chez les Alticinae (Coleoptera, Chrysomelidae). Bulletin Mensuel de la Société Linnéenne de Lyon 60 (2): 53-72.

Konstantinov, A.S. 1998. On the structure and function of the female genitalia in flea beetles (Coleoptera: Chrysomelidae: Alticinae). Proceedings of Entomological Society of Washington 100 (2): 353-360.

Powell, E.F. 1941. Relationships within the Family Chrysomelidae (Coleoptera) as indicated by the male genitalia of certain species. American Midland Naturalist 25: 148-195.

Revista Brasileira de Zoologia 24 (3): 552-558, setembro 2007 
Scherer, G. 1983. Diagnostic Key for the Neotropical Alticine Genera (Coleoptera: Chrysomelidae: Alticinae). Entomologische Arbeiten aus dem Museum G. Frey 31/32: 1-89.

Silva, A.G.A.; C.R. Gonçalves; D.M. Galvão; A.J.L. Gonçalves; J. Gomes; M.M. Silva \& L. Simoni. 1968. Quarto catálogo dos

Recebido em 23.IV.2007; aceito em 02.VII.2007. insetos que vivem nas plantas do Brasil, seus parasitos e predadores. Parte II $-1^{\circ}$ Tomo - Insetos, hospedeiros e inimigos naturais. Rio de Janeiro, Ministério da Agricultura, Departamento de Defesa e Inspenção Agropecuária, XXVIII+ 622p. 